\title{
The calculative turn in land value capture: lessons from the English planning system
}

\section{Article}

\section{Accepted Version}

Creative Commons: Attribution-Noncommercial-No Derivative Works 4.0

McAllister, P. (2017) The calculative turn in land value capture: lessons from the English planning system. Land Use Policy, 63. pp. 122-129. ISSN 0264-8377 doi:

https://doi.org/10.1016/j.landusepol.2017.01.002 Available at https://centaur.reading.ac.uk/69596/

It is advisable to refer to the publisher's version if you intend to cite from the work. See Guidance on citing.

To link to this article DOI: http://dx.doi.org/10.1016/j.landusepol.2017.01.002

Publisher: Elsevier

All outputs in CentAUR are protected by Intellectual Property Rights law, including copyright law. Copyright and IPR is retained by the creators or other copyright holders. Terms and conditions for use of this material are defined in the End User Agreement.

\section{www.reading.ac.uk/centaur}

\section{CentAUR}

Central Archive at the University of Reading

Reading's research outputs online 


\section{Introduction}

In England, for over three decades planning obligations have been the main mechanism by which the community has been able to capture some of the uplift in land values 'released' by planning permission. Since around 2005, there has been an incremental but major shift in how policy regarding planning obligations has been formed and how planning obligations are negotiated for individual development schemes. This has involved financial viability becoming a central consideration in planning policy making and development management. In essence, ostensibly to ensure that development is deliverable, a viability test involves a quantitative calculation of whether policies regarding planning obligations compromise a "competitive" financial return to the land owner and the developer. In a period of high levels of policy innovation and/or volatility in the English planning system, this has been a fundamental change in the planning regime. In policy making, the main application of financial viability modelling has been in the formation of local planning policy regarding planning obligations (mainly requirements for non-market housing provision and contributions to education, health, infrastructure and other community facilities). Following the introduction of the Community Infrastructure Levy in 2012, local planning authorities were also required to apply financial viability tests to assess whether it would compromise deliverability. For specific development schemes, viability calculations have been at the nexus of community opposition to proposed major regeneration projects. It is the scheme, rather than policy making, level that is the main focus of this paper where issues of methodology and process in viability calculations have been extremely controversial (see Colenutt, Cochrane and Field, 2015).

In the context of development management, particularly where a proposed development does not comply with policy, viability tests are increasingly being used as the basis for negotiating (and renegotiating) planning obligations for individual proposed development projects. Whilst prima facie viability appraisal might seem like a straightforward, technical test, in practice it has proved very contentious. Providing an impression of technocratic rationality, development viability appraisal can be conceptualised as a calculative practice that has become increasingly embedded in the English planning system. A common attraction of quantification and technical models is that they appear to involve an apparently value neutral process. However, their use can be associated with a tendency for unquestioning, institutionalised trust in numbers and, by reconfiguring subjective and contestable judgements as pseudo-scientific, may permit essentially political processes to be presented as technical procedures (Mennicken et al, 2008). Given their implications for the allocation of land value uplifts between communities and land owners, the application of these apparently technocratic procedures has become increasingly controversial. In July 2015, Boris Johnson, the Mayor of London, described financial viability assessments as "something of a dark art". In this paper, the 
focus is on the operational issues that have emerged in the application of viability calculations in the English planning system.

There is limited codified knowledge on the use of viability tests. A great deal of what we 'know' about the role of viability tests is based upon the fragmented, often impressionistic, observations of market participants and planning professionals and case studies of specific schemes. There has been no systematic research into the extent and nature of the use of viability tests in development management processes. Similarly, there is little explicit knowledge on the procedures in place to evaluate viability appraisals. How consistent and rigorous are evaluation procedures? Do local authorities and the Planning Inspectorate have the necessary expertise to adjudicate on viability issues? Tension between the commercial confidentiality of developers and community participation in and the transparency of the planning process has been a particularly controversial issue with a number of adjudications by the Information Commissioner's Office.

This paper provides a formative, process evaluation of the introduction of financial viability criteria into development management via the use of development viability calculations. The approach to evaluation is 'realist' in that the objective is to establish what it is about the policy that works (or does not work), for whom and in what circumstances? Whilst the use of viability appraisal models has become increasingly controversial, there has been limited evaluation to date of the application of these calculative procedures. It also needs to be acknowledged that, given the ideological and distributional salience of this issue, researcher objectivity is problematic. Indeed, most academic researchers engaged in this area have been involved in writing guidance and advising governmental, professional and/or community organisations. As such, the contribution of academics such as Peter Wyatt and Bob Colenutt has been both performative and analytic or descriptive ${ }^{1}$. Given this point and limited documented empirical research, the evaluation draws substantially on an element of participant action research. Whilst there are varying degrees of 'insiderness', the researcher's participation in a range of relevant events and meetings, personal relationships with key participants and contributions to various consultation exercises provided multiple points of access to key concerns and perspectives on the topic. This access, in addition to a review of documented analysis, empirical research and inference, informs this evaluation.

\section{Viability as a Policy Construct}

\footnotetext{
${ }^{1}$ For instance, Bob Colenutt has appeared as appeared as an expert on viability issues before the Greater London Assembly Planning Committee and has appeared as a witness on viability issues at Freedom of Information tribunals. Peter Wyatt is a member of the RICS Committee that produced the RICS' Financial Viability in Planning guidance and continues to be involved in drafting updated guidance.
} 
In this paper, the introduction of financial viability criteria into planning policy formation and development management is framed as a policy innovation. Whilst policy making is often understood to involve explicit articulation of activities undertaken by government, often through legislation, to achieve outcomes, policy can also be tacit or implicit and, rather than being formally stated, can be inferred from practice. It may even involve a decision to be inactive. The introduction of financial viability criteria into planning policy formation and decisions does not fit easily into a rationalist policy formulation model such as the 'Rationale $\rightarrow$ Objectives $\rightarrow$ Appraisal $\rightarrow$ Monitoring $\rightarrow$ Evaluation $\rightarrow$ Feedback' cycle. Lindblom's (1959) depiction of ad hoc, incremental, policy evolution by a 'muddling through' process of trial-and-error reflects the (almost certainly) unintended consequences of the introduction of financial viability criteria into the planning system. In this specific context, the 'morphogenesis' of the policy as it has mutated in form and grown in scope and scale has created 'winners' and 'losers' (Pawson et al., 2005). In turn, as the policy of applying financial criteria has evolved and grown in scope and scale, there has also been a process of policy learning by central government policy makers, local planning authorities, professional institutions and community activists among others.

It is difficult to identify an explicit theory or rationale for the policy change. Central government planning policy makers did not make it explicit (at least to the public) how they believed that this policy instrument was going to work before its implementation. The underlying policy theory seems to have been implicit. Within the broad objective of increasing the supply of both non-market and market housing, the policy of financial viability testing seems to have been introduced in order to promote development stalled by the 'burden' of planning obligations that was rendering it financially unviable and ensure that sites were not allocated for development where it was not financially feasible to develop. Viability modelling could also provide a basis for local authorities to demonstrate that their policies on planning obligations were consistent with appropriate economic incentives for land owners and developers. The rationale for the use of viability calculations seems to have been to provide an objective mechanism for calculating the amount of planning obligations that could be generated by a project. It is unlikely that the policy of introducing financial viability criteria into planning decisions was initially designed to achieve some of the outcomes that have emerged. Indeed, it is difficult to identify any conventional policy design at all.

Given the scope and scale of the policy of using financial viability appraisals in planning decisions and policy making, an assessment of the outcomes of this policy change is particularly challenging. Many assumptions about appropriate measures, causal mechanisms and timescales would be highly contestable. As in most policy innovations, a major problem in evaluation is the absence of valid counterfactuals. It is widely assumed that the introduction of viability appraisals has enabled developers to decrease the level of land value capture through planning obligations than would 
otherwise have occurred. However, it is extremely challenging to robustly estimate whether observed outcomes are the products of policies changes. In addition, as noted above, the policy has evolved and expanded in scope over time. As such, the focus of this paper is on the process rather than the outcomes.

It is also important to appreciate the wider housing policy context in which the policy of using viability calculations in planning has emerged. Arguably the calculations and related guidance on their application could easily have evolved to favour the interests of the community. At a presentation in 2015, Duncan Bowie (a former advisor on housing policy to the Mayor of London) outlined how, in the period 2001-2003, he pioneered ago the use of viability modelling. In 20012003 , his aim was to provide a robust evidence base that could demonstrate that a planning policy of requiring provision of 50\% non-market housing could be feasible in many areas of London. When viability appraisals initially emerged in negotiations on planning obligations, generally developers were (and remain) reluctant to 'open their books' and were resistant to the viability process. In 2006, planning guidance from central government was exhorting local planning authorities to be more proactive in seeking planning obligations and "to recognise that such obligations will increasingly be viable on new housing developments". However, the Coalition government (and its Conservative successor) formed in 2010 proved to be more sympathetic to the interests of land owners and private sector house builders. In particular, a myriad of major policy initiatives and relatively minor pieces of policy guidance seem to reflect a broad policy prejudice against the provision of non-market, rental housing ${ }^{2}$ - the single most important source of community gain from planning obligations (DCLG, 2013).

As noted above, the policy of introducing financial viability criteria in planning policy making and development management seems to have emerged in an incremental and ad hoc manner. Circulars and Planning Policy Statements were the main instruments by which the policy was communicated to local planning authorities by the central government department responsible for national planning policies. Essentially their planning circulars and policy statements provide non-statutory advice and guidance on particular issues to expand on subjects referred to in legislation. They are used to explain policy and regulation more fully. Circulars can be quasi-legislative and include a direction or requirement to take specific action or provide guidance on implementation of aspects of planning

\footnotetext{
${ }^{2}$ A few examples...The Growth and Infrastructure Act 2013 permitted developers to obtain reductions in previously agreed and legally binding levels of planning obligations. However, the level of provision of nonmarket housing was the only planning obligation which could be amended. The Vacant Building Credit introduced in 2014 enabled developers to be exempt from planning requirements for non-market housing if the space being redeveloped was vacant. More broadly, in 2015 the government proposed to give tenants of housing associations a 'right to buy' their rental dwelling from the housing association at a discount to market value.
} 
policy. Circulars and PPS can be interpreted as policy documents or "information instruments" that basically urge local authorities to do what government deems appropriate (Vedung and van der Doelen, 1998, p. 103). Additional 'information instruments' may then set out how policies should progress from general principles to practice. Table 1 sets out the chronology of policy documents that referred to the financial viability of development as a criterion for development management and/or planning policy making. However, no procedural guidance was initially provided to local authorities on how the policy was to be implemented. It has largely been left to local planning authorities individually to operationalise this policy initiative.

As is discussed below, a wide range of issues have needed to be addressed as the policy of using viability calculations has been implemented. Given the vacuum in terms of guidance on policy implementation, professional bodies (e.g. RICS, RTPI), lobbying organisations (e.g. the Local Government Association) and quasi-autonomous government agencies (e.g. Homes and Communities Agency) proposed their own 'rules' for undertaking viability calculations and the related evaluation and consultation processes. In 2016, Islington Borough Council was the first local planning authority to introduce detailed and comprehensive guidance on viability calculations. Inevitably, the documents (or models) produced have reflected to various degrees the particular perspectives and interests of these organisation's members and stakeholders. A decade after the Circular in 2005, clearly implying some problems in how they are being used, the central government in its 2015 budget statement committed itself to bringing forward proposals for a more standardised approach to viability assessments.

\section{Development viability calculations: key principles}

The basic calculations underpinning development viability appraisal modelling are relatively simple. As applied, it is a simple, rule-based, data model that involves estimating the costs and revenues from a development project. Conventionally, the land value (often term the residual land value) is calculated as the difference between the value of the development project and the cost of developing the project. This principle provides the basis of the standard calculative techniques that are used to estimate the value of development land or assets with development potential. The basic calculation is:-

$$
R L V=D R-(D C+D P)
$$

Where $R L V$ is residual land value, $D R$ are expected revenues generated by the development, $D C$ are the expected costs of development and $D P$ is required developers' profit or return. 
Table 1

\section{Financial Viability in Planning: Key Policy Documents and Events}

1998 Circular 6/98: Planning and Affordable Housing stated that when using planning obligations to deliver affordable housing, local authorities should 'take account of the needs of developers and registered social landlords who must ensure that schemes are financially viable.' However, formal modelling of project viability as part of planning processes did not begin.

2001 Consultants (Three Dragons) commissioned by the GLA assessed viability of affordable housing policy across London and created a development appraisal 'toolkit' adapting long-established development appraisal models.

2005 Circular 5/05: Planning Obligations stated that 'In some instances,...it may not be feasible for the proposed development to meet all the requirements set out in local, regional and national planning policies and still be economically viable...decisions on the level of contributions should be based on negotiation with developers over the level of contribution that can be demonstrated as reasonable to be made whilst still allowing development to take place'. Formal modelling of project viability begins to be used for development management and planning policy making.

2006 A Communities and Local Government document Delivering Affordable Housing stated that "[E]ffective use of planning obligations to deliver affordable housing requires...realistic affordable housing targets and thresholds given site viability." However, it is notable that the objective is to enable local authorities to "raise their game and to recognise that such obligations will increasingly be viable on new housing developments".

2006 Planning Policy Statement 3: Housing stated that Local Development Documents should "reflect an assessment of the likely economic viability of land for housing within the area"

2008 Planning Policy Statement 12: Create Safe, Strong and Prosperous Communities through Local Spatial Planning emphasised justification of planning policy choices and a credible evidence base to support them. It also stated that local authorities should ensure "that partners who are essential to the delivery of the plan such as landowners and developers are signed up to it."

2012 The National Planning Policy Framework (2012) stated the planning authorities should pay "careful attention to viability".

2013 The Growth and Infrastructure Act permitted developers to obtain reductions in already agreed levels of non-market housing 'based on prevailing viability...supported by relevant viability evidence’ (DCLG, 2013: 4).

2015 In the Government's Spending Review and Autumn Statement, it is stated that "[T]he government will bring forward proposals for a more standardised approach to viability assessments, and extend the ability to appeal against unviable section 106 agreements to 2018." 
Whilst they can be disaggregated into much more detail, development costs broadly consist of a range of construction, professional fees, planning obligations and land transfer taxes. Developers' profit is a commonly expressed as a \% of development costs or development revenues or as an internal rate of return. Planning obligations and the Community Infrastructure Levy (CIL) affect both the costs and revenues. Development revenues will usually be lower if there is a requirement to provide non-market housing. Planning obligations concerning infrastructure provision and contributions to the provision of education, health and transport facilities may be provided 'in kind' by the developer or cash contributions. They will tend to increase development costs. Finally, the viability test is that if the estimated (residual) land value is sufficiently in excess of the value of the land in its current use to incentivise the owner to sell the land, then it is concluded that development is financially viable. This involves a comparison of the calculated land value with an estimate of, what has been termed, threshold or benchmark land value. This latter concept has been probably the single most contested issue in development viability calculations and is discussed further below.

\section{Development Viability Modelling: Problems in Practice}

Whilst there has been a long established body of criticism of the current system of planning obligations as a mechanism of value capture e.g. deadweight losses, regressive, payment in advance of earnings, lack of relationships with externalities generated etc. the evaluation below not does not address these wider, systemic issues (see Healey, Purdue and Ennis, 1996). The focus here is on the policy of using a specific calculative technique as part of the development management process. Jakeman et al, (2006) summed up very well some of the broad risks intrinsic to the use of technical models in public policy contexts.

\footnotetext{
"The uses of models by managers and interest groups, as well as modellers, bring dangers. It is easy for a poorly informed non-modeller to remain unaware of limitations, uncertainties, omissions and subjective choices in models. The risk is then that too much is read into the outputs and/or predictions of the model. There is also a danger that the model is used for purposes different from those intended, making invalid conclusions very likely" (Jakeman et al, 2006, 603).
}

To date, empirical research has focussed on the use of development viability appraisals in the formation of area-wide policy regarding land value capture through planning obligations (see Coleman et al., 2013 and McAllister et al. 2015). Problems of policy obsolescence and lack of applicability to local site and market conditions were highlighted. A key issue is that, in the local planning policy making context, development viability models are effectively estimating whether planning policies that will be implemented in the future on actual sites compromise the current financial viability of hypothetical projects. In addition, less fundamentally the consultation process 
was essentially limited to experts and community participation was absent until policy proposals were formed.

Whilst resultant policies will create policy aspirations for specific development projects, the use of viability appraisals for individual projects in the development management process has been much more controversial. Potential losses and gains are actual rather than hypothetical, they are shortterm rather than medium or long term, are being realised by individual developers rather than expressed as a policy and, are conclusive rather than being the commencement of a process of setting planning obligations for a scheme. Gains and losses to the developer and/or landowner often directly correspond to losses and gains for the local community in the form of non-market housing, community facilities etc. While there are weaknesses common to both uses of viability appraisals (area-wide local planning policy formation or scheme-specific local planning policy implementation), in this paper the focus is on the implementation of local planning policies regarding planning obligations at the development management stage. The problems of viability appraisals are categorised in terms of; technical theoretical weaknesses in appraisal models, input and output uncertainty, problems of moral hazard and perverse incentives and weak governance.

\section{Model structure uncertainty}

Whilst the development appraisal models or techniques that have emerged from this Ricardian principle of residual surplus have been applied by the real estate development sector for many decades, there has always been a degree of model structure uncertainty. Model structure uncertainty is caused by the processes of simplification and formulation inherent to any modelling ( $\mathrm{Wu}$ and $\mathrm{Li}$, 2006). In practice, a range of development appraisal models are used that incorporate different approaches to: the timing of costs and revenues; whether cost and revenue inflation should be incorporated; the inclusion of and assumptions about debt; and the appropriate metric of return or profitability (see Crosby et al, 2013). In turn, these model structure uncertainties are also present in development appraisal models when applied in the planning context for viability calculations (see Crosby and Wyatt, 2015). A significant number of these model structure uncertainties have been criticised in terms of their theoretical robustness. They may well persist in practice, because in terms of generating model output uncertainty, the level of model structure uncertainty is dominated by uncertainty in the model inputs (Byrne et al, 2012).

\section{Input and output uncertainty}


It has long been recognised that development appraisals are prone to input uncertainty. Half a century ago, in a Lands Tribunal decision, it was stated that "it is a feature of the residual valuation that comparatively minor adjustments to the constituent figures can have a major effect on results ..." and "once valuers are let loose on residual valuations, however honest the valuers and however reasoned their argument they can prove almost anything", First Garden City Ltd v Letchworth Garden City Corporation (1966) 200 EG 123, 460. Accordingly, the residual valuation would be accepted by the Lands Tribunal only as a method of 'last resort'. However, in the absence of an alternative calculative technique, this method of last resort is essentially the basis of current viability calculations. The apparent ability to prove almost anything is largely due to intrinsic uncertainty in the model inputs.

As noted above, development viability modellers are essentially trying to estimate the development costs of a project (including a normal ${ }^{3}$ profit for the developer) and the revenues from the development. Outside the planning context, the most important model input assumptions tend to concern construction costs and sale prices. Other variables tend to be a proportion of these figures e.g. professional fees are often taken as a percentage ${ }^{4}$ of construction costs. Development viability modellers are faced with uncertainty in current price and cost levels and uncertainty in changes in prices and costs over the development period. The development period itself is also subject to uncertainty. Due to these uncertainties, nearly all the key inputs into a development viability appraisal can be estimated within a defensible range. For instance, for a hypothetical apartment project, assumptions regarding construction costs anywhere between $£ 2000$ and $£ 2500 \mathrm{psm}$, sale prices anywhere between $£ 11,000$ and $£ 12,000 \mathrm{psm}$, professional fees anywhere between $8 \%$ and $11 \%$ of construction costs etc. may all be defensible and reasonable.

It has been in planning appeals where the assumptions of viability models have come under most public scrutiny. In one planning appeal (Appeal Ref: APP/K5600/A/09/2097458 Parkes Hotel, 41-43 Beaufort Gardens, London SW3 1PW) for a site in a prime central London location, a developer was able to demonstrate that the proposed project was unviable at any level of planning obligations. They argued that they were undertaking the project at a financial loss as part of a long-term strategy. The Inspector's judgement illustrates glaringly potential for disagreement in outputs due to input uncertainty.

\begin{abstract}
"The toolkit evidence produced on behalf of the appellant by Cushman \& Wakefield shows a deficit of $£ 7,663,007$, without any affordable housing being provided. It was submitted that the appellant would incur an overall loss on the project, but that this would be accepted as part of his long term aspiration to carry out improvements to Beaufort Gardens (and to allow further profit in the future). The appellant's toolkit result is tested against a number of different scenarios, including the designation of Unit $5 \mathrm{~B}$ as social rented housing and using
\end{abstract}

\footnotetext{
3 'Normal' in this context is based upon the economic concept of a minimum profit necessary to attract and retain suppliers in a competitive market.

${ }^{4}$ However, the percentage itself may also be prone to uncertainty. For example, broker's fees may be assumed to be $0.5 \%$ or $0.6 \%$ etc. of sale prices. Other variables are factual. For instance, Stamp Duty is currently $4 \%$ of sale price of residential development land.
} 
the District Valuer's opinion of market value and EUV. All of these scenarios produce a negative result.

21. Toolkit evidence on behalf of the Council was provided by the District Valuer. With no affordable housing provision, the "against residual" figure shows a positive sum of $£ 11,792,000$. With 1 affordable unit (5B), the figure would be reduced to $£ 10,822,000$ and, with 2 affordable units (1B \& 5B), £10,338,000.22. These are significantly different results, arising in the main from a number of disputed input values. Evidence for both parties was given by professionally qualified and experienced surveyors and valuers and I do not attempt to determine which figures are "correct."

What constitutes a competitive return to the developer or a normal profit has also been the topic of some controversy. Whilst Christophers $(2013,75)$ points disapprovingly to "normalization" of profit and perceives that profit "remains paramount, endemic" - somehow privileged, it is difficult to see how profit cannot be a factor in a market-led system of housing supply. Further, whilst viability models make an allowance for expected developers' profit, the actual level of profit on completion of the project is still subject to major uncertainty, is dependent on uncertain future revenues and costs and, consequently, can be substantially higher or lower than expectations. Rather than the principle of profit itself, in practice the main issue concerning developers' profit in the viability context has been the assumption of what should, prior to development, be an expected normal profit. There can be a propensity in using technical models to seek simple, stable and general inputs. In reality, a robust process for estimating some inputs can be complex, the inputs can be variable over time and can also be variable with the specific situation.

Required profit tends to be closely linked to project risk which is driven by a range of project-specific and market-systematic factors. Market drivers will vary over time driven by the interaction of local and macroeconomic performance and the capital markets. Individual projects will have different risk profiles. With or without planning permission? Phased or single building? Long-term or short-term? Pre-let or speculative? Greenfield or brownfield? So required profits levels should vary over time for the same project and vary between projects at any given point in time. In practice, and perhaps not surprisingly, in the context of viability appraisals in the planning system developers have been attempting to set high profit benchmarks. A $20 \%$ profit on revenue or a $20 \%$ internal rate of return per annum (both are quite different profit metrics) have emerged as benchmarks through, as one consultant commented personally to the author, "a mix of chutzpah and naivety". Nevertheless, it remains the fact that operationalising such concepts as a competitive return is problematic. However, the most controversial concept to operationalise has been a competitive return to the land owner rather than a competitive return to the developer.

Whilst most inputs into a viability model are prone to uncertainty in their estimation, this is essentially due to imperfect information. There can also be uncertainty in the interpretation of an input. In most cases, the test of viability has been whether, at a given level of planning obligations, the residual land value is higher than, what is often termed, Threshold Land Value or Benchmark Land Value. This land value threshold or benchmark is meant to determine what constitutes a competitive return to the land owner and where this 
benchmark is set is the key variable determining land value capture. If the viability model output is a land value that is higher than the Threshold or Benchmark Land Value, then the planning obligations are regarded as deliverable. Perhaps not surprisingly, the setting of Threshold Land Value has been at the heart of the controversy regarding the application of development viability modelling. In the last decade, a blend of the professional bodies, local authorities, professional bodies and others have been trying to define the concept in their own interests with a range of perspectives being proposed.

Many of the issues have been aired comprehensively in previous research (see Crosby and Wyatt, 2015 and Coleman et al, 2013) The debate has crystallised into a contest about whether the threshold should be based upon the Existing or Alternative Use Value of the land or the current Market Value of the land. Whilst land owners and their representatives have favoured a Market Value based approach, the main criticism has been that there is a problem of circularity. Market Value estimates are often based on the transaction prices of similar sites. However, since land prices are influenced by the level of planning obligations, there is a risk that developers' expectations of planning obligations implied in achieved land prices then constrain the level of planning obligations that are viable on other sites. Central government seems to have been unwilling to provide clear guidance on this crucial issue. Most of the guidance produced until recently has contained a degree of ambiguity.

In its Planning Policy Guidance Note, the Department for Communities and Local Government stated that

"In all cases, land or site value should:

- $\quad$ reflect policy requirements and planning obligations and, where applicable, any Community Infrastructure Levy charge;

- $\quad$ provide a competitive return to willing developers and land owners (including equity resulting from those wanting to build their own homes); and

- $\quad$ be informed by comparable, market-based evidence wherever possible. Where transacted bids are significantly above the market norm, they should not be used as part of this exercise.

The first and third bullet points are key and are not necessarily aligned. They have been given different weights in planning appeals. In a 2015 planning appeal for a site in central London (Appeal Ref: APP/V5570/A/14/2227656 Former Territorial Army Site, 65-69 Parkhurst Road, London N7 OLP), the Planning Inspector displayed a very good understanding of the issues. He focussed on the topic of whether Existing Use Value should form the basis for estimating a competitive return to the land owner or whether it should be based on current land prices evidenced by transactions. Since the precedent is so central to land value capture in the English planning system, the Inspector's judgement is worth quoting at some length.

\footnotetext{
"In this context I can understand the wider concern of the Council about the possible effect of inputting purchase prices which are based on a downgrading of the policy expectation for affordable housing on the eventual outcome of a scheme viability appraisal. If such prices are used to justify a lower level of provision, developers could then in effect be recovering the excess paid for a site through a reduced level of affordable housing provision. Such a circularity has been recognised in research for the RICS,
} 
and the Council in its SPD and the GLA (in its Development Appraisal Toolkit Guidance Notes of 2014) are alive to this potential outcome of using purchase price as an input in viability assessment. The Council postulates an undesirable scenario of diminishing returns of affordable housing and eradication of the potential to achieve its delivery. It argues that the current appeal is an opportunity to return to a proper approach..."

However, it becomes clear that the Inspector places more weight on the third bullet point from the Planning Policy Guidance rather than the first one.

“...the PPG stresses the need to take account of market signals. The only information on such signals in this case supports the use of the appellant's land value figure. Importantly, the evidence does not suggest that a reasonable landowner would be incentivised to release the land for development at the value suggested by the Council. The options for a rational owner in a rising market include that of holding onto the land rather than selling it below a value indicated by the market. This is consistent with national guidance which seeks to avoid jeopardising viability. The boosting of housing development in general terms assists in the supply of affordable housing. National policy is firmly in favour of realism and flexibility where the viability of a development is in question. In this case, the market evidence supports a higher valuation for the site than that used by the appellant and the scheme is strictly not viable on the current figures. Taking all of the above into account, the appellant's land value figure (roughly what they paid) can be regarded as adequately reflecting policy requirements on affordable housing. Bearing in mind that the development plan policy is to seek the maximum reasonable rather than the maximum possible amount of affordable housing, on the available evidence of the current position I consider that what is being offered in this case would achieve that."

Islington Council have been at the vanguard in attempting to resist this shift towards land prices for nonpolicy compliant projects becoming the benchmark for testing viability and generating consequent reductions in land value capture. Since this appeal, they have introduced their own guidance (Development Viability: Supplementary Planning Document, January 2016) which promotes Existing Use Value as the appropriate benchmark and, perhaps predictably, focuses on the first bullet point in the Planning Policy Guidance

“... a key factor in determining the benchmark land value (and the level of premium over EUV) is the requirement set out in PPG that in all cases land or site value should reflect planning policies, planning obligations and CIL. This has the direct consequence of ruling out significantly inflated land values arising from the grant of permission, based on assumptions (built into purchase prices, transactions and/or land owner aspirations) which do not adequately reflect planning policy. These inflated values would, if adopted, make it almost inevitable that those policy requirements would be found to be unviable. Such an approach conflicts with the statutory planning framework and undermines the plan-led system as established in the Town and Country Planning Act 1990 (as amended) and the NPPF.

This conceptual contest which is crucial and central to land value capture continues.

The estimation of viability model inputs in the planning context is then being determined by the interaction of a broad range of technical, regulatory, political, ideological, market and behavioural factors, If the choice of model inputs were independent, it would be expected that some estimates of individual inputs would be at the upper end of the defensible limits; others would be at the lower end. However, if development viability modellers systematically opt for pessimistic but reasonable and defensible assumptions in the development viability appraisals submitted in support of planning applications, land values or expected 
returns will be underestimated. Whilst each individual model assumption may be reasonable and defensible, collectively the model inputs will be systematically biased. Given that the output of such models - estimated land values or returns - can be very sensitive to relatively small changes in major inputs such as construction costs or sale prices, the implications for estimated planning obligations can be substantial. Intrinsic uncertainty in the model inputs and consequent output uncertainty create the means by which development viability models can be systematically biased. The process by which viability appraisals are formed produces an opportunity for opportunism.

\section{Incentives and Governance}

Given the financial trade-offs involved in land value capture, it is not surprising that land owners have major economic incentives to influence the outputs of viability models. Broadly, over the last two decades a habitual issue has been deep disquiet about the ethics of information intermediaries such as rating agencies, auditing firms and equity analysts (see Lin and McNichols, 1998 and Michaely and Womack 1999 on equity analysts; for ratings agencies see Bolton, Freixas and Shapiro, 2012; and for auditing firms see Gaver and Paterson, 2007). Real estate appraisal has been lower profile but there is also a well-established body of research that finds consistent evidence that clients can bias real estate appraisal outcomes (see Crosby et al, 2015 for a review). Termed economic dependence, the blend of individual and business incentives to attract and retain client fees in a context of inadequate regulatory oversight has been seen on numerous occasions to produce unethical bebaviour.

The vast majority of development viability appraisals are produced by consultants. This quotation from Norman Ralph Augustine perhaps identified the potential problem too bluntly - "All too many consultants when asked 'What is two plus two?' respond 'What do you have in mind?'” For areawide viability calculations commissioned by local authorities, McAllister et al. (2015) found that limited economic incentives, weak understanding of the viability techniques by local politicians and planners, reputational risks for consultants, the participation of local market participants and public scrutiny of outputs provided sufficient controls on potential opportunistic behaviour by local planning authorities. For scheme-specific viability calculations, the contrast is stark. They are commissioned by land owners. It is the land owner who pays for the viability appraisal ${ }^{5}$. As noted above, there are substantial economic incentives for the land owner and the consultant to produce biased appraisals. The land owner themselves is often an expert on development appraisal and can

\footnotetext{
${ }^{5}$ It also seems to be the case the land owner pays for any evaluation of their appraisal by an expert appointed by the local planning authority. This can create a relationship of economic dependence between the consultant scrutinising the viability appraisal and the land owner.
} 
exploit inherent input uncertainty to their advantage. The viability calculations are typically confidential and not subject to public scrutiny.

Guidance on the conduct of viability appraisals is beginning to emerge that attempts to control for potential opportunistic behaviour. The Islington SPD on development viability appraisal introduced a requirement for a statutory declaration from the applicant company confirming that the assessment submitted to the council is a true and fair reflection of the viability of the proposed development; and that costs and values in this assessment are consistent with current costs and values within (or used as a starting point for) viability assessments that have been undertaken for internal or financial purposes. In addition, the declaration should state that the company undertaking the assessment has not been instructed on the basis of performance related pay or is incentivised in any other way according to the outcome of the viability process and the level of planning obligations that the applicant is required to provide. However, given the facts that any viability appraisal is a snapshot at a fixed point in time, that there is intrinsic uncertainty in the inputs and that economic dependence is embedded in the production of viability appraisals, it is difficult see how such requirements can effectively reduce the scope for bias.

The inability of the community to scrutinise viability models has also been a source of considerable dispute. There is a well-established body of work on public participation and transparency in the planning system (see Sheppard, Burgess and Croft, 2015 for a review). De Fine Licht (2014) demonstrates the relationships between perceived transparency, perceived fairness and decision acceptance. Adams and Watkins $(2014,18)$ argue that:

"Democratic participation that enhances public understanding and acceptance of controversial development projects is a more effective way to secure the legitimacy and acceptance of long-term investment decisions than resort to the courts."

In England, whilst a number of high profile cases have gone to the Information Commissioner for adjudication, land owners and developers have generally been able to submit viability models on a private and confidential basis. The Information Commissioner has had to judge whether the potential damage to the economic interests of the developer or land owners should take precedence over the benefits of transparency. Potential harm for developers has focussed on disclosure of commercially valuable information, protection of commercial bargaining positions, avoidance of commercially significant reputational damage and disclosures that could would otherwise result in a loss of revenue or income. Judgements by the Information Commissioners have been inconsistent. In some cases, full disclosure has been ordered, on others partial disclosure has been recommended and no disclosure has been recommended in a number of cases. In the most recent case, regarding the redevelopment of a shopping centre in Hackney, London, the Information Commissioner concluded that "The public interest in favour of disclosure is outweighed by the public interest in maintaining 
Table 2 A Summary of the Key Limitations of the Use of Development Viability Calculations for Development Management

Problems

Model input uncertainty

Output uncertainty

Ambiguous guidance on competitive

return to the land owners

Conflicting guidance

Poor transparency

Model structure uncertainty

\section{Incentives to bias inputs}

Potential non-independence of

consultants

Complex and costly process

10 Lack of expertise in planning profession

\section{Type}

Information

uncertainty

Result uncertainty

Contested guidance

Weak governance

Weak governance

Weak technique

Moral hazard

Moral hazard

Weak technique

Knowledge

limitations

\section{Primary cause}

Imperfect information

Input uncertainty

Lack of consensus

Lack of consensus

Procedural weakness

Persistence of poor practice

Production process

Procedural weakness

Large range of data required

Lack of experience and

education

\section{Importance Preventable? Comments}

High

High

High

No

Yes

High

Yes

High

Yes

Low

Yes

High

Yes

High

Yes

Low

Yes

Low
Requires clear and authoritative

guidance

Requires clear and authoritative

guidance

Requires clear and authoritative

guidance

Requires clear and authoritative guidance

Requires viability calculators to be

independent

Requires viability calculators to be

independent

Simpler approaches are possible

Independent advice can be

procured and/or better education 
the exception." (ICO, 2015: 17). Whilst Islington BC have attempted to embed public disclosure in their SPD, despite the fact that the main purpose of submitting viability appraisals is to justify a lower level of land value capture by the community, the vast majority of viability appraisals remain unavailable to the community.

\section{Conclusion}

In the last decade, viability calculations have become progressively embedded in many parts of the plan making and development management processes of the English planning system. Largely through planning obligations, these calculative techniques have thus become a central component of the land value capture process. Whilst it is generally presumed that the quantity of land value capture has reduced because of the introduction of viability calculations, there is a need for research that investigates the effects of viability testing on the amount of land value capture and other impacts. How much development has occurred that would not otherwise have occurred? How much nonmarket housing, community facilities etc. have been 'lost'? Estimating these counterfactuals raises important and challenging empirical research questions.

The focus of this paper has been largely on the process of viability testing and on evaluating whether viability calculations are fit for purpose. In practice, the purpose of the policy of applying viability calculations was not made explicit. Its applications imply that the purpose was to provide a rational basis for testing whether planning policies, including policies for land value capture, can be "delivered" by market participants. In the development management context, as a neutral tool, viability calculations are essentially being used to calculate the capacity for value capture from a proposed project. A key problem is that the calculations are prone to substantial intrinsic uncertainty in a large number of the model inputs. Whilst calculations provide an impression of scientific precision, this is spurious. The key inputs into development viability appraisals are saturated with uncertainty. The result is a large degree of uncertainty in the outputs and, therefore, the potential value capture. Land value capture that is based on such outputs is, to some (also uncertain) extent, capricious. This is unavoidable and it may be a cost that is outweighed by the potential benefits of viability calculations. However, this intrinsic model input uncertainty produces a contest over the calculations and, in turn, facilitates opportunistic behaviour.

Although it's an evolving topic with new guidance and precedents regularly emerging, a key issue in the use of viability applications has been poor governance and competing guidance. Given the clear incentives for developers and land owners to bias viability calculations, the economic dependence of many viability consultants on developers and land owners, the lack of transparency, 
contested or ambiguous guidance and the opportunities created by input uncertainty for bias, it should not be surprising that land owners tend to be able to demonstrate that they are unable to comply with policies on planning obligations. This tendency has been occurring in a city with some of the highest land values in the world. Of course, weaknesses in guidance and governance can be addressed - if there is a political will.

Given the broader political and planning policy context in which viability calculations have become so prevalent, it would be a "rationalist's fantasy" to ignore the power strategies and micro-politics involved in viability calculations (Forester, 1999, 177). Even if there is the political will to 'standardise' the process of viability calculations, of course procedural guidance can be shaped to favour different interests. Networks of government ministers, civil servants, policy advisors, political parties, lobbying groups, corporations, professional bodies, think-tanks, activists etc. constitute the policy venues or deliberative arenas which, even to insiders, are often only partially visible and who have been trying to shape how viability calculations are produced. Developers and land owners have been better resourced than local authorities and, debateably, have had a more sympathetic hearing from a Government that has been eager to stimulate the private housing market. The unresolved equivocality surrounding the concept of Threshold Land Value provides a striking illustration of ambiguity that has been constructive from the perspective of land owners and destructive from the perspective of the wider community. 


\section{Bibliography}

Adams, D. and Watkins, C. (2014). The Value of Planning, RTPI Research Report no.5

Bolton, P., Freixas, X. and Shapiro, J. (2012) The Credit Rating Game, Journal of Finance, 67, 85-112.

Byrne, P., McAllister, P. and Wyatt, P. (2011) Precisely Wrong or Roughly Right? An Evaluation of Development Viability Appraisal Models, Journal of Financial Management in Property and Construction, 16, 3, 249-271.

Christophers, B. (2014). Wild Dragons in the City: Urban Political Economy, Affordable Housing Development and the Performative World-making of Economic Models. International Journal of Urban and Regional Research, 38, 79-97.

Coleman, C., Crosby, N., McAllister, P. and Wyatt, P. (2012) Development Appraisal in Practice: Some Evidence from the Planning System, Journal of Property Research, 30, 122.

Colenutt, R. Cochrane, A. and Field, M. (2015). The rise and rise of viability assessment. Town and Country Planning, 84, 453-458.

Crosby, N., Devaney, S., Lizieri, C. and McAllister, P. Can Institutional Investors Bias Real Estate Portfolio Appraisals? Evidence from the Market Downturn, Journal of Business Ethics, in press.

Crosby, N., McAllister, P. and Wyatt, P. Fit For Planning? (2012) An Evaluation of the Application of Development Viability Appraisal in the UK, Environment and Planning B, 40, 1, 3-22.

de Fine Licht, J., (2014). Policy area as a potential moderator of transparency effects: An experiment. Public Administration Review, 74, 361-371.

DCLG (2012) National Planning Policy Framework, Department for Communities and Local Government: London.

DCLG (2013) Section 106 affordable housing requirements: Review and appeal, Department for Communities and Local Government: London.

Forester, J. (1999) Reflections on the future understanding of planning practice, International Planning Studies, 4, 175-193.

Gaver, J. J., and Paterson, J. S. (2007). The influence of large clients on office-level auditor oversight: Evidence from the property-casualty insurance industry. Journal of Accounting and Economics, 43, 299-320. 
Healey P, Purdue M Ennis F, 1996 "Negotiating development: planning gain and mitigating impacts", Journal of Property Research 13 143-160

Jakeman, A. J., Letcher, R. A., and Norton, J. P. (2006). Ten iterative steps in development and evaluation of environmental models. Environmental Modelling \& Software, 21, 602-61.

Lin, H. and McNichols, M. (1998) Underwriting Relationships, Analysts' Earnings Forecasts and Investment Recommendations. Journal of Accounting and Economics, 25, 101-127.

Lindblom, C.E., 1959. The science of" muddling through". Public Administration Review, 79-88.

Mennicken, A., Miller, P., and Samiolo, R. 2008. Accounting for economic sociology, Economic Sociology, 10, 3-6.

Michaely, R. and Womack, K. (1999) Conflict of Interest and the Credibility of Underwriter Analyst Recommendations. The Review of Financial Studies, 12(4), 653-686.

McAllister, P., Street, E. and Wyatt, P. Governing Calculative Practices: An Investigation of Development Viability Modelling in the English Planning System, Urban Studies, in press

McAllister, P., Wyatt, P. and Coleman, C. (2013) Fit for Policy? Some Evidence on the Application of Development Viability Modelling in the UK Planning System, Town Planning Review, 84, 495-521.

Pawson, R., Greenhalgh, T., Harvey, G. and Walshe, K., (2005) Realist review - a new method of systematic review designed for complex policy interventions. Journal of Health Services Research and Policy, 10, 21-34.

Sheppard, A., Burgess, S. and Croft, N., (2015). Information is Power: Public Disclosure of Information in the Planning Decision-Making Process. Planning Practice \& Research, 30 , 443-456.

Vedung, E. and van der Doelen, F. (1998) The Sermon: Information Programs in the Public Policy Process - Choice, Effects, and Evaluation, in Bemelmans-Videc, M., Rist, R. and Vedung, E., (Eds.), Carrots, Sticks, and Sermons: Policy Instruments and their Evaluation. Transaction Publishers, New Brunswick, NJ, London, UK, pp. 103-128.

Wu, J. and Li, H. (2006). Uncertainty analysis in ecological studies: an overview, Scaling and Uncertainty Analysis in Ecology, 45-66. 
